\title{
ENFERMEDAD POR CORONAVIRUS 2019 (COVID-19): ¿PREVALECERÁ LA ECONOMÍA O LA VIDA EN TIEMPOS DE PANDEMIA?
}

\section{CORONAVIRUS DISEASE 2019 (COVID-19): WILL THE ECONOMY OR LIFE PREVAIL IN TIMES OF PANDEMIC?}

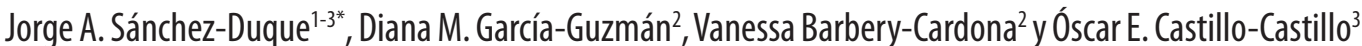
'Grupo de Investigación Salud Pública e Infección, Facultad de Ciencias de la Salud, Universidad Tecnológica de Pereira, Pereira, Risaralda; 2Departamento de Medicina Social y Salud Familiar, Grupo de Investigación Salud, Familia y Sociedad, Facultad de Ciencias de la Salud, Universidad del Cauca, Popayán, Cauca; 'Latin American Network of Coronavirus Disease 2019-COVID-19 Research (LANCOVID-19), Pereira, Risaralda; ‘Facultad de Ciencias de la Salud, Fundación Universitaria San Martín, seccional Cali, Cali, Valle del Cauca. Colombia

\section{Señor editor,}

Durante las últimas décadas, el mundo se ha expuesto a una serie de brotes virales emergentes de diferente índole, sin embargo, la enfermedad por coronavirus 2019 (COVID-19), causada por el coronavirus 2 del síndrome respiratorio agudo grave (SARS-CoV-2), ha logrado un impacto clínico, político y económico sin precedentes, de modo que fue declarada por la Organización Mundial de la Salud como una emergencia de salud pública de importancia global y catalogada como pandemia el 30 de enero y 11 de marzo de 2020, respectivamente $^{1,2}$.

Los primeros casos reportados en Wuhan (República Popular de China) fueron el 12 de diciembre de $2019^{1,2}$, sin embargo su propagación ha sido tal que, a la fecha de 23 de abril de 2020, el número total de casos registrados en el mundo es de 2,783,512, de los cuales, EE.UU., España e Italia presentan el mayor número de casos, con 886,213 (31.84\%), 219,764 (7.90\%) y
192,994 (6.93\%) respectivamente, y los restantes se distribuyen en otros 188 países. El número de muertos supera los 195,313, encabezados por EE.UU., Italia y España, con $50,780(26.00 \%), 25,969(13.30 \%)$ y 22,524 (11.53\%) muertes respectivamente ${ }^{3}$.

A pesar de las medidas tomadas en la mayoría de los países, debido a que no existe una vacuna o un tratamiento específico para el SARS-CoV-2, día a día el número de casos y el número de muertos aumentan exponencialmente, de modo que se estima un número de muertes que podría rondar entre 1 y 2 millones de personas al finalizar el brote, razón por la cual es difícil exagerar las devastadoras consecuencias que este dejará a nivel global en otros sectores como el económico $^{2,4,5}$.

Numerosos holocaustos inducidos por brotes virales emergentes y reemergentes han causado pérdidas económicas importantes, ejemplos recientes incluyen al virus Ébola y al SARS-CoV-1, los cuales comportaron pérdidas estimadas de 25.2 y 40 billones de dólares respectivamente ${ }^{4}$. Sin
Correspondencia:

*Jorge A. Sánchez-Duque

E-mail: jorandsanchez@utp.edu.co
Fecha de recepción: 25-04-2020

Fecha de aceptación: 15-05-2020
Disponible en internet: $31-07-2020$

Rev Mex Med Fam. 2020;7:78-9 DOI: 10.24875/RMF.20000072 
embargo, estas estimaciones parecen irrelevantes al lado del SARS-CoV-2, el cual podría tener un impacto económico global incluso superior a 1.1 trillones de dolares ${ }^{4-6}$.

Es indudable que la economía será uno de los sectores más afectados, con pérdidas económicas multimillonarias, sin embargo la mayoría de estimaciones son inexactas, debido a la no inclusión de factores directos e indirectos asociados a la preparación y prevención (prácticas que mitigan el riesgo), el evento en sí (por ejemplo, gastos por atención médica, interrupción de cadenas de suministro y prohibición de viajes de comercio) y las secuelas del evento (por ejemplo, pérdidas de empleo a largo plazo, impacto en educación perdida y discapacidad y mortalidad temprana en población laboralmente activa), variables que claramente se encuentran condicionadas por el comportamiento final de la pandemia ${ }^{4-7}$.

El personal de la salud basa su trabajo en el juramento hipocrático, sin embargo su capacitación en economía es limitada; por otra parte, los economistas, hábiles en evaluar costos y beneficios de las conductas, no pueden poner en la balanza valores inciertos asociados a la epidemiología del brote. Como si fuera poco, las determinaciones en salud pública son tomadas por los gobiernos, quienes deben considerar ambas opiniones y preocupaciones en la toma de decisiones de las medidas ideales para cada país. Por ello es importante que el personal de salud disponga de bases sólidas, científicas y éticas para orientar la balanza hacia el bien de la población ${ }^{4,5}$.

Comprendiendo que la presencia de estos brotes es inevitable y deja consecuencias devastadoras para la sociedad, se debe considerar la actual pandemia como un recordatorio de la necesidad imperiosa de mejorar los sistemas de salud y de economía de cada país ${ }^{2,5,7}$. El primero para desarrollar estrategias preventivas útiles para la prevención y el control de las pandemias que incluyan mayor inversión en investigación, implementación de herramientas como la telemedicina y obtener un mayor número de servicios de cuidados intensivos para el soporte de pacientes $\operatorname{críticos}^{5-8}$; y el sector económico mediante implementación de mayor número de empleos remotos y diversificación de los ingresos, entre otras estrategias $^{2,5,7}$.

Ante desafíos como la actual pandemia por SARS-CoV-2, se requiere un papel de liderazgo en salud pública que promueva la colaboración entre sector salud y sector economía, entre entidades públicas y privadas, donde se cuente con un apoyo constante de todas las partes interesadas, como medios de comunicación, población en general y el sector salud, lo cual configura un urgente llamado a la medicina familiar ${ }^{5-8}$.

\section{BIBLIOGRAFÍA}

1. Sánchez-Duque JA, Arce-Villalobos LR, Rodríguez-Morales AJ. Enfermedad por coronavirus 2019 (COVID-19) en América Latina: Papel de la atención primaria en la preparación y respuesta. Aten Primaria. 2020. DOI: 10.1016/j.aprim.2020.04.001 [Epub ahead of print]

2. Rodríguez-Morales AJ, Sánchez-Duque JA, Hernández-Botero $S$, Pérez-Díaz CE, Villamil-Gómez WE, Méndez CA, et al. Preparación y control de la enfermedad por coronavirus 2019 (COVID-19) en América Latina. Acta Med Peru. 2020;37(1):3-7.

3. Dong E, Du H, Gardner L. An interactive web-based dashboard to track COVID-19 in real time. Lancet Infect Dis. 2020;20(5):533-4.

4. Maffioli EM. How is the world responding to the 2019 coronavirus disease compared with the 2014 West African Ebola epidemic? The importance of China as a player in the global economy. Am J Trop Med Hyg. 2020;102(5):924-5.

5. Hilsenrath PE. Ethics and economic growth in the age of COVID 19: What is a just society to do? J Rural Health. 2020 Apr 3. doi: $10.1111 /$ jrh.12434. Online ahead of print.

6. Nicola M, Alsafi Z, Sohrabi C, Kerwan A, Al-Jabir A, losifidis C, et al. The socio-economic implications of the coronavirus and COVID-19 pandemic: A review. Int J Surg. 2020;78:185-93.

7. King JS. Covid-19 and the need for health care reform. N Engl J Med. 2020 Apr 17. doi: 10.1056/NEJMp2000821. Online ahead of print.

8. Muñoz-Abril YC, Hernández-Rincón EH, Avella-Pérez LP. Rol del médico familiar en el nuevo modelo integral de atención en salud en Colombia. Rev Cuba Med Gen Integr. 2019;35(3):e466. 